\title{
Predicting career success: is the dark side of personality worth considering?
}

\author{
Dominik Paleczek, Sabine Bergner and Robert Rybnicek \\ Department of Corporate Leadership and Entrepreneurship, \\ University of Graz, Graz, Austria
}

\begin{abstract}
Purpose - The purpose of this paper is to clarify whether the dark side of personality adds information beyond the bright side when predicting career success.

Design/methodology/approach - In total, 287 participants $\left(150 \%, M_{\text {age }}=37.74\right.$ and $\left.S D_{\text {age }}=10.38\right)$ completed questionnaires on the Dark Triad (narcissism, Machiavellianism and psychopathy) and the Big Five (emotional stability, extraversion, openness, agreeableness and conscientiousness). They also provided information on their objective (salary and leadership position) and subjective (job satisfaction and satisfaction with income) career success. Regression analyses were used to estimate the Dark Triad's incremental predictive value.

Findings - The results show that the Dark Triad only provides incremental information beyond the Big Five when predicting salary $\left(\Delta R^{2}=0.02^{*}\right)$ and leadership position $\left(\Delta R^{2}=0.04^{*}\right)$. In contrast, the Dark Triad does not explain unique variance when predicting job satisfaction or satisfaction with income.

Research limitations/implications - The exclusive use of self-rated success criteria may increase the risk of same-source biases. Thus, future studies should include ratings derived from multiple perspectives.

Practical implications - Considering the Dark Triad in employee selection and development seems particularly promising in the context of competitive behaviour.

Social implications - The results are discussed in light of the socioanalytic theory. This may help to better understand behaviour in organisational contexts.

Originality/value - This study is the first that simultaneously investigates all three traits of the Dark Triad and the Big Five in combination with objective and subjective career success. In addition, it extends previous findings by answering the question of whether the Dark Triad offers incremental or redundant information to the Big Five when predicting success.
\end{abstract}

Keywords Dark Triad, Career success, Big Five, Socioanalytic theory, Personality

Paper type Research paper

\section{Introduction}

Success at work is undoubtedly one of the most important challenges to nearly everyone during adulthood. Because it is often argued that individual success is related to organisational success (Judge et al., 1999), identifying appropriate predictors and thereby improving the predictability of career success is a major concern for researchers and practitioners. In addition to cognitive intelligence (Hülsheger and Maier, 2008), it has been demonstrated that personality traits are also important (Judge et al., 1999). The latter play a particularly crucial role in so-called "weak" situations in which the leeway in decision making is large and therefore decisions and behaviours strongly rely on a person's character (Seibert et al., 1999).

The focus of this investigation is to examine whether the prediction of career success can be enhanced by considering the "dark" side of personality in addition to the "bright" side.

C Dominik Paleczek, Sabine Bergner and Robert Rybnicek. Published by Emerald Publishing Limited. This article is published under the Creative Commons Attribution (CC BY 4.0) licence. Anyone may reproduce, distribute, translate and create derivative works of this article (for both commercial and non-commercial purposes), subject to full attribution to the original publication and authors. The full terms of this licence may be seen at http://creativecommons.org/licences/by/4.0/legalcode
Received 13 November 2017 Revised 19 May 2018 22 August 2018

5 September 2018

Accepted 6 September 2018 
JMP

33,6

438

More precisely, we elucidate how far the Dark Triad (Paulhus and Williams, 2002) is able to predict career success beyond the commonly used Big Five (Costa and McCrae, 1992). The current study builds on the work of Spurk et al. (2016), who recently examined the Dark Triad's relationship to career success and extends their findings by investigating whether the Dark Triad offers incremental or redundant information to the Big Five when forecasting career success.

Since "the Big Five model has provided a unifying taxonomy for the study of personality, which is essential to the communication and accumulation of empirical findings" (Cable and Judge, 2003, p. 198), this study bridges an evident research gap. Referring to the Big Five as the standard taxonomy enables the evaluation of the Dark Triad's relative importance in occupational contexts for both theory and practice. In other words, if the Dark Triad adds additional information beyond the Big Five, then it justifies its use as a novel predictor for career success. To the best of our knowledge, no study has examined this topic until now. Before explaining our research assumptions, we will describe the conceptualisation of career success and briefly summarise the findings on its link to behaviour and personality.

\section{Career success}

To provide a comprehensive picture of career success, it is important to consider both the objective and subjective components of an individual's career (Heslin, 2005). While objective career success is defined as verifiable (in principle) by an impartial third party (Hughes, 1937), subjective career success refers to a person's individual evaluation of professional experiences and achievements (Abele et al., 2011). In this regard, salary, leadership position or the number of promotions represent "visible" achievements and therefore are commonly used indicators for objective career success. These indicators can either be assessed via self-ratings (e.g. Seibert et al., 1999; Spurk et al., 2016) or via work records (e.g. Heslin, 2005). In contrast, job satisfaction, satisfaction with the personal income or career satisfaction are frequently employed measures to assess subjective career success as they describe how individuals emotionally perceive their careers (Boudreau et al., 2001; Judge et al., 1995; Spurk et al., 2016). In this study, we employ salary and leadership position to operationalise objective career success and job satisfaction and satisfaction with income to indicate subjective career success. The way these criteria are influenced by behaviour strategies and personality traits is outlined in the following sections.

\section{Behaviour strategies and career success}

To understand behaviours in organisational contexts and to further predict differences in career success, we delve into psychological processes that motivate individuals to show these behaviours. From an evolutionary perspective, behaviour is mainly driven by basic needs to maximise reproductive success such as seeking status, protecting kin or finding mates (Jonason et al., 2014). These basic needs are more easily satisfied when holding an advanced position in the social hierarchy and being respected and valued by others (van Vugt and Tybur, 2016). Even though appreciation by others is fundamental to most of us for the above-mentioned reasons, it paradoxically motivates some individuals to follow different behaviour strategies than others. The socioanalytic theory (Hogan and Holland, 2003) provides a useful approach to explain these individual differences. Given that first, people live and work in groups and second, groups are structured in a hierarchical way, the socioanalytic theory distinguishes between two main behaviour strategies that might be pursued to gain status and strengthen one's own hierarchical position. These strategies are termed "getting-along" and "getting-ahead".

Getting-along behaviour strategies are described as being cooperative, supporting, and prosocial, whereas getting-ahead behaviour strategies refer to sharp-elbow tactics and 
competition seeking. According to Hogan and Holland (2003), the division of behaviour along these two broad and complementing motive patterns reflects a wide-ranging idea, for example, when discussing theories on social interests and superiority striving (Adler, 1939), communion and agency (Bakan, 1966; Wiggins, 1991) or status and popularity (Hogan, 1983). Even in theories on evolution, this dichotomy of complementing strategies can be identified, for instance, when contrasting Margulis' (1991) ideas of symbiosis (getting-along) with Darwin's (2013) assumptions on the struggle for existence (gettingahead) or when studying Maynard Smiths' hawk-dove analogy, which addresses the evolutionary game theory (for details please see Dawkins, 1976). Although these approaches employ different terms to label the two behaviour strategies, they all share a common core that individuals either aim at living in (peaceful) coexistence with others or focus on personal advancement gained at the expense of others.

Since these two behaviour strategies (getting-along and getting-ahead) fundamentally differ from each other, they influence outcomes differently or even shape completely different outcomes. With respect to individual careers, this indicates that getting-along and getting-ahead behaviours are relevant for different aspects of career success. To influence (getting-ahead triggered) outcomes, such as salary or leadership position, individuals must take the initiative and claim a pay raise or seek competition to get ahead of others and achieve improved positions in the hierarchy. In contrast, being satisfied reflects a rather non-competitive, calm, and social orientation (Foote and Li-Ping Tang, 2008), which is why this aspect of career success is more likely assigned to the gettingalong domain.

During one's career, an individual commonly shows both getting-ahead and getting-along strategies. However, individuals also have a personal preference for one strategy over the other and this preference is strongly determined by the individuals' personalities (Hogan and Holland, 2003). To delineate how traits might affect an individual's career, we subsequently summarise the findings on the personality-career success link and on the relationship between personality and behaviour strategies.

\section{Personality and career success}

The Big Five. The Five-Factor model (Costa and McCrae, 1992), which is also known as the Big Five, is certainly the most widely accepted and most frequently used personality taxonomy when predicting occupational behaviour and career success (Barrick et al., 2001). It comprises the five factors of emotional stability, extraversion, openness, agreeableness and conscientiousness. Emotional stability describes an individual's impulse control, mood control, and resistance to emotional stress. Extraversion denotes the extent to which an individual feels comfortable engaging in direct social interactions with others. Extraverted individuals are assertive, dominant, energetic, active, talkative and enthusiastic. Conscientiousness describes the extent to which a person is organised, self-disciplined, dutiful and achievement striving. Openness refers to a preference for thinking and understanding problems, seeking out new experiences, having aesthetic interests, and tending to be reflective about emotions or behaviours. Finally, agreeableness refers to an individual's courteous, trusting, considerate and cooperative demeanour.

Initially, the Big Five appear to be mostly beneficial and desirable, which is why they are often regarded as the "bright" side of personality. However, the Big Five also have potential downsides in their extremes (Smith et al., 2017). For instance, highly emotionally stable individuals are sometimes perceived as unconcerned or emotionally detached. Strongly extraverted individuals may be regarded as self-centred attention seekers who push themselves to the fore, whereas extremely conscientious persons often lack spontaneity. 
JMP

33,6

Moreover, highly open individuals may be described as unfocussed or less committed at work and strongly agreeable persons can be seen as submissive or even naive.

Regarding their impact at work, a vast number of primary studies and meta-analyses demonstrate that the Big Five are valid predictors of career success with emotional stability, extraversion and conscientiousness showing particularly strong and positive correlations with almost every success criterion. Barrick et al. (2001) reported in a second-order meta-analysis that emotional stability and conscientiousness are the most valid and stable predictors of work performance, which also relates to career success. Judge, Heller and Mount (2002) further showed that emotional stability and extraversion positively relate to job satisfaction in almost every study. Additional findings support the importance of extraversion and demonstrate its positive link to salary (Seibert and Kraimer, 2001), leader emergence, leadership effectiveness (Judge, Bono, Ilies and Gerhardt, 2002) and training proficiency (Barrick and Mount, 1991). In brief, emotionally stable, extraverted and conscientious individuals are more likely to be successful at their jobs and careers. The remaining Big Five traits, agreeableness and openness, also seem important for career success but their validity strongly depends on the chosen success criterion and the occupational context. Thus, no generalisable expectations are typically formulated concerning the relationship between career success and these two personality traits (e.g. Judge et al., 1999; Ng et al., 2005). In summary, studies employing the Big Five have clarified substantial parts of the relationship between personality and career success. Nevertheless, alternative personality models have recently gained attention in this field of research.

The emergence of alternative personality models. As outlined above, the Big Five have received great attention in past decades and have evolved into the "scientific standard" when discussing personality. Even though the Big Five are conceptualised to depict an individual's character in all of its facets, upcoming research advises against being overly reliant on the Big Five. Current findings suggest that the Big Five cover darker aspects of personality to a lesser extent than the brighter ones (Harms and Spain, 2015; Jonason et al., 2014; Veselka and Vernon, 2014). For example, certain words and lexical clusters that crucially describe dispositions conducive to showing competitive (getting-ahead) behaviour (e.g. "evil" or "dangerous") have simply not been considered when conceptualising the Big Five (Harms and Spain, 2015). Emerging evidence suggests that the Big Five could be extended by a honesty-humility factor, which (on its negative pole) describes darker aspects of an individual's personality and is already integrated in the HEXACO model (Lee and Ashton, 2004). In summary, although the Big Five represent a valid and important model for predicting career success it seems to miss out on the darker aspects of personality that may be important, especially for the prediction of getting-ahead outcomes. A current approach is to subsume those darker aspects of personality into the so-called Dark Triad (Paulhus and Williams, 2002).

The Dark Triad. In comparison to the bright side of personality (as represented by the Big Five), the influence of dark traits on daily work routine seems underexplored even though newspaper headings and book titles, such as Snakes in Suits (Babiak and Hare, 2006) or Bad Bosses: The Psycho-path to Success (Voight, 2012), reflect an upcoming interest in this topic.

Paulhus and Williams (2002) initially subsumed the (subclinical) personality traits of narcissism, Machiavellianism and psychopathy under the term Dark Triad. All three traits share the common core that individuals scoring high on any of them operate in a socially aversive way. Consequently, the Dark Triad's impact at work is rather negative. Therefore, the Dark Triad is associated with counterproductive work behaviour (O'Boyle et al., 2012), low self-control (Jonason and Tost, 2010), or the use of abusive and destructive interpersonal tactics (Jonason et al., 2012). These behaviours make it difficult to 
get along with a person and therefore might also reduce work outcomes that rely on getting-along with others (Anninos, 2018).

However, like the downsides of bright traits, there are also upsides of dark traits. These upsides might foster work outcomes that rely on getting-ahead behaviours like demonstrating superiority and power. Therefore, individuals showing such behaviours might be noticed and promoted more often by their leaders and also show better career advancement (Andreassen et al., 2012). In this regard, it is interesting that individuals that score high on dark traits more successfully gather key resources from their surroundings and are better at putting emotions aside when making decisions (Smith et al., 2017). Behaving this way makes them appear more competent, which may further foster career advancement. Consequently, it is assumed that individuals scoring high on the Dark Triad also have certain advantages at work (Barrick et al., 2002).

In summary, there are certainly situations in which acting in a darker manner may be beneficial for an individual's career advancement and there are situations in which the Dark Triad reveals its adaptive side; however, in other situations the hindering aspects may be more apparent. To investigate the positive and negative consequences of the Dark Triad in detail, each of its three traits must be considered separately as they are accompanied by distinct needs and caused by distinct underlying motivations.

Narcissism. Narcissists have a strong need to be admired by others. They constantly aim at strengthening their sense of grandiosity, pride and egotism by using tactics like self-enhancement or seeking the attention of others, but narcissists also use detrimental strategies like devaluing others (Morf and Rhodewalt, 2016; Paulhus and Williams, 2002). At work, these competitive strategies (to get ahead of others) result in both positive and negative career outcomes. The narcissistic need for being admired and recognised might push narcissists to show higher levels of work investment than their colleagues. For example, this is supported by Andreassen et al. (2012) who showed that narcissists are more engaged in their work. Moreover, a narcissists' sense of grandiosity leads them to publicly express their self-perceived superiority over others, for instance, by devaluing others or exaggerating their personal achievements. Thus, they often create the impression of being more competent and effective than others (Brunell et al., 2008). Given that qualities like work engagement, competency and effectiveness increase objective career success (Rowold and Heinitz, 2007; Xanthopoulou et al., 2009), it can be assumed that narcissists display higher objective career success. This assumption is clearly supported by findings demonstrating that narcissists achieve higher positions (Wille et al., 2013), more often emerge as leaders (Brunell et al., 2008) and receive higher earnings (Spurk et al., 2016; Wille et al., 2013).

Nevertheless, narcissism might also impede certain aspects of career success, in particular, those that rely on subjective evaluations and non-competitive, calm and social interpersonal (getting-along) behaviour. Narcissistic people may feel unsatisfied with their present career and judge the quality of any alternative career better than less narcissistic people judge. Likewise, findings on romantic relationships support this view by showing that narcissists see alternative partners as more appealing than their less narcissistic counterparts do (Campbell and Foster, 2002). A narcissists' sense of grandiosity might also foster their belief that they are overqualified for a job, which may decrease their job satisfaction (Mathieu, 2013). As such, narcissism supposedly relates to subjective outcomes like job satisfaction and satisfaction with personal income in a negative way. In conclusion, narcissism is supposed to positively relate to objective career success while negatively correlating with subjective career outcomes.

Machiavellianism. Machiavellians have a strong need for power, status and money. The essence of Machiavellian behaviour is commonly reflected by the gist "the end justifies the means", which also implies the tendency to use manipulative strategies to achieve goals. 
JMP

33,6

442

Machiavellians readily accept other people's disadvantages when maximising their own benefits and thus do not feel tied to moral values (Paulhus and Williams, 2002).

In the context of careers, a Machiavellians' strong need for power, status and money may particularly push their longing for objective career outcomes, such as leadership positions or high income, as these reflect power and status. It is likely that Machiavellians use their ability to employ manipulative strategies as well as their willingness for unethical behaviour to gain a competitive advantage at work, which helps them to increase objective career outcomes. Empirical findings support these assumptions and show that Machiavellians are less willing to share important knowledge at work to maintain advantages when it comes to making the right decisions (Liu, 2008). Furthermore, they are more likely to blow the whistle on their colleagues to put themselves in a better position (Tang and Chen, 2008). Such behaviour might be beneficial in achieving objective career success and thus might explain why Machiavellians more often end up in leadership positions (Spurk et al., 2016).

Besides the positive effects on objective career success, Machiavellianism also relates to certain negative behaviours, which primarily reduce the quality of interpersonal relationships (getting-along). For instance, Machiavellians are perceived as abusive supervisors (Wisse and Sleebos, 2016) or show counterproductive work behaviour (O'Boyle et al., 2012), high dominance and low affiliation (Gurtman, 1992; Locke and Christensen, 2007). Considering the deficiency in affect and the antisocial behavioural style manifested in Machiavellianism it is not surprising that this personality trait is linked to poor intimate relationship quality (Jonason et al., 2009). However, as the quality of interpersonal relationships is important for individual satisfaction (Arrindell et al., 2001), this suggests that Machiavellians show lower satisfaction at work. In brief, Machiavellianism is supposed to positively relate to objective career success while negatively correlating with subjective career outcomes.

Psychopathy. Individuals high on the subclinical psychopathy spectrum show low selfcontrol, which results in a strong need to follow sudden impulses. Their behaviour is best described by terms like selfishness, cold affectedness and a lack of empathy. Those with a high tendency for subclinical psychopathy do not fear negative consequences even when these lead to self-destruction (Paulhus and Williams, 2002).

Even though subclinical psychopathy appears to be the darkest trait among the Dark Triad, it is not exclusively negative in a career context. The tendencies of a psychopath to be fearless, show superficial charm and have a lack of remorse may be beneficial in careers as they help to make necessary but unpleasant decisions (Osumi and Ohira, 2010). Therefore, persons with higher psychopathic tendencies might easily dismiss employees, bluff and lie in business negotiations to achieve advantages or remorselessly intimidate others. These getting-ahead behaviours might help them to achieve prestigious positions and greater objective career success, which could also explain why subclinical psychopaths show higher entrepreneurial tendencies (Akhtar et al., 2013) and are more often found in leadership and management positions as well as in high-risk occupations such as criminal prosecution (e.g. Lilienfeld et al., 2014).

However, it is evident from various findings that psychopathy may also influence personal careers in a negative way. This holds particularly true for career outcomes that rely on getting-along with others (e.g. organisational commitment) (Boddy et al., 2010). As the quality of one's interpersonal relationships is critical to the evaluation of subjective career outcomes, such as satisfaction or wellbeing (Lyubomirsky et al., 2005), and a psychopaths' relationships are shallower and poorer quality, it is assumed that psychopathy negatively relates to subjective career success. This reasoning is supported by findings showing that psychopathy is linked to severe forms of counterproductive work behaviour 
(O’Boyle et al., 2012) and lower career satisfaction (Spurk et al., 2016). Consequently, psychopathy is assumed to negatively relate to subjective career outcomes while positively correlating with objective career success.

\section{Personality and behaviour strategies}

As outlined above, personality validly predicts behaviour and different personality traits trigger different behaviour strategies (Judge et al., 2009). These behaviour strategies, in turn, influence different career outcomes. In this regard, Oh and Berry (2009) showed that the Big Five can be directly linked to those behaviour strategies described by socioanalytic theory. More detailed, Oh and Berry combined the idea of getting-along and getting-ahead behaviour with the framework of the Big Five when predicting work performance, which is a criterion related to career success. Their findings suggest that the Big Five subsume so-called getting-along traits (e.g. agreeableness), which are mainly linked to getting-along behaviour like supporting colleagues or being prosocial at work. Additionally, but to a lesser extent, the Big Five comprise getting-ahead traits (e.g. openness), which are primarily linked to getting-ahead behaviour such as achievement striving, trying to be recognised or taking initiative. Oh and Berry further state that getting-ahead traits are more suitable for predicting those performance criteria that are typically achieved by ambitious and self-serving behaviour, whereas getting-along traits better predict those criteria that are usually achieved by being compliant and cooperative.

Of importance for this study, the Dark Triad (in contrast with the Big Five) subsumes traits that trigger extreme forms of getting-ahead behaviour as it describes a mindset that is totally focused on getting-ahead at the expense of getting-along (Furnham et al., 2013; Jonason et al., 2015). Demonstrating superiority, authority and entitlement (narcissism) (Andreassen et al., 2012), showing high need for achievement and using any tactic to influence others no matter how destructive it might be (Machiavellianism) (Dahling et al., 2008; Kessler et al., 2010) or demonstrating a lack of concern for other people and social norms (psychopathy) clearly describes a pronounced getting-ahead attitude (Furnham et al., 2013; Jonason et al., 2015). Consequently, it is suggested that the Dark Triad complements the Big Five in covering the darker side of personality because the Big Five represents this side in a less comprehensive manner. This is exactly the point where the present study further examines this relationship.

\section{The present study}

Based on the theoretical background outlined above, this study focuses on whether the Dark Triad offers incremental or redundant information to the Big Five when forecasting career success. Addressing this question is particularly important because using the Dark Triad for the prediction of career success is only justified if it adds additional information beyond the standard taxonomy of personality research (i.e. the Big Five).

We argue that the Dark Triad adds validity beyond the Big Five when forecasting career success. In this context, two aspects are important to note. First, according to the socioanalytic theory, getting-ahead traits are more suitable to predict getting-ahead criteria of success, whereas getting-along traits better predict getting-along criteria $(\mathrm{Oh}$ and Berry, 2009). Second, the dark side of personality, which fosters extreme forms of getting-ahead behaviour, is insufficiently represented by the Big Five and can be more comprehensively covered by the Dark Triad (Harms and Spain, 2015; Jonason et al., 2014; Lee and Ashton, 2014; Veselka and Vernon, 2014). Consequently, the Dark Triad might offer information concerning getting-ahead criteria that is not addressed in the Big Five. As a result, we expect the Dark Triad to add incremental validity beyond the Big Five when 
JMP

33,6

444

predicting the getting-ahead criteria of salary and leadership position as these criteria are rather influenced by getting-ahead behaviours. With respect to the prediction of the gettingalong criteria of job satisfaction and satisfaction with income, we assume that the incremental validity of the Dark Triad over the Big Five is less clear. The latter mentioned criteria are rather affected by consequences of getting-along behaviours, such as good interpersonal relations or mutual respect, which should be sufficiently covered by the Big Five. Consequently, the following hypotheses $(\mathrm{H})$ are tested:

H1. Each of the Dark Triad traits (narcissism, Machiavellianism and psychopathy) is positively related to self-reported salary after controlling for the Big Five traits.

H2. Each of the Dark Triad traits (narcissism, Machiavellianism and psychopathy) is positively related to leadership position after controlling for the Big Five traits.

H3. Each of the Dark Triad traits (narcissism, Machiavellianism and psychopathy) is negatively related to job satisfaction after controlling for the Big Five traits.

H4. Each of the Dark Triad traits (narcissism, Machiavellianism and psychopathy) is negatively related to satisfaction with income after controlling for the Big Five traits.

\section{Method}

\section{Participants and procedure}

In total, the study sample consisted of 287 German-speaking employees (150\%, $M_{\text {age }}=37.74$ and $S D_{\text {age }}=10.38$ ) from diverse organisations and fields (e.g. the automobile industry, tourism, business, education and medical and health industry). Altogether, 144 participants had leading responsibilities. The participants had worked in their occupational careers for an average of 16.6 years $(S D=11.57)$. Participation was voluntary, anonymous and online. Data were collected for research purposes; no hiring decisions were based on the data.

Participants were recruited using different communication channels and all of these were free of charge. These channels were diverse in an effort to reach a broad variety of participants and included the use of social media, intranet webpages of local companies, local HRM platforms and word-of-mouth recommendations. To establish a trustworthy relationship, it was guaranteed that no data would be passed on to the participants' employers. The study participants received written feedback on their personality scores to compensate them for their efforts.

\section{Measures}

Personality traits. Big Five. The Big Five were assessed using the NEO-PI-R-90 (Oppriessnig and Neubauer, 2012), which is a shortened version of the NEO-PI-R (Costa and McCrae, 1992). This questionnaire consists of 90 items that are completed on a five-point Likert scale ranging from 1 (strongly disagree) to 5 (strongly agree). Each of the Big Five traits is assessed by 18 items that cover 30 lower-level facets. The following items represent samples for the five bright traits: "I have a lot of intellectual curiosity" (Openness); "When I make a commitment, I can always be counted on to follow through" (Conscientiousness); "I am dominant, forceful, and assertive" (Extraversion); "I try to be courteous to everyone I meet" (Agreeableness); and "I am an even-tempered person" (Emotional Stability). We obtained Cronbach's $\alpha$ values between 0.74 and 0.87 for the five personality factors (please see the values in parentheses on the main diagonal of Table I).

Dark Triad. To measure the Dark Triad, three personality questionnaires that are frequently used to operationalise narcissism, Machiavellianism and psychopathy were applied. 


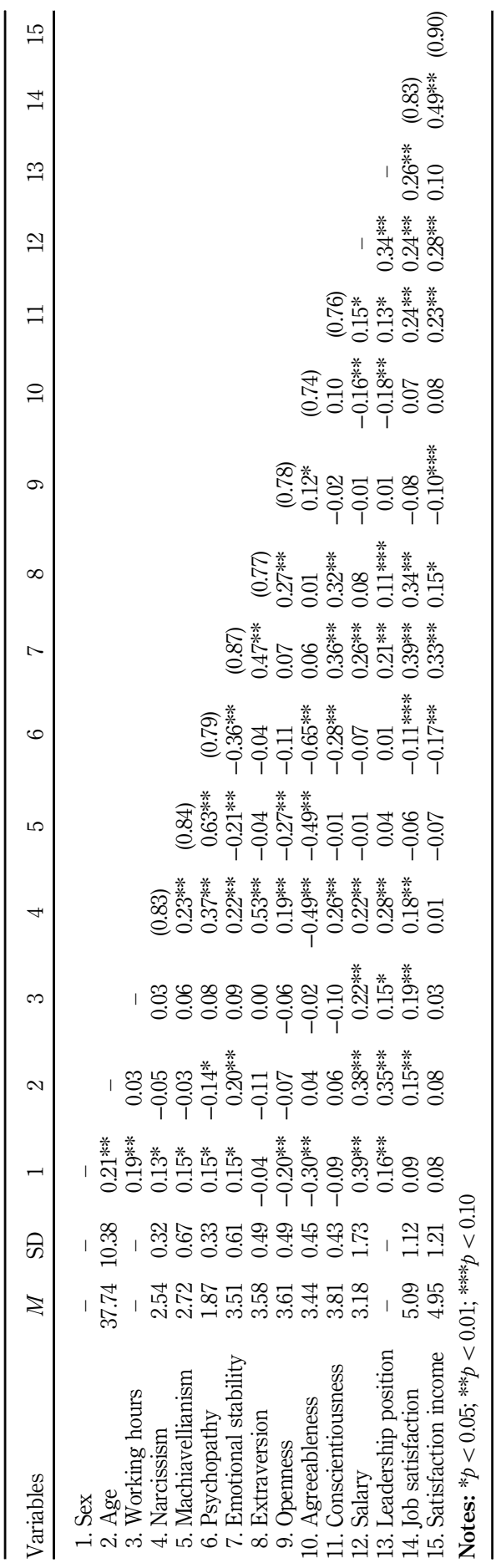

\section{Predicting career success}

445

Table I.

Means $(M)$, standard deviations $(S D)$, and Cronbach's $\alpha$ (diagonal), as well as intercorrelations among study variables 
JMP

33,6

Narcissism was assessed by the Narcissistic Personality Inventory (NPI-R; Raskin and Hall, 1979; revised German version by Zimmermann, 1994). In total, this questionnaire is comprised of 40 items (sample item: "I am an extraordinary person") that were rated on a four-point Likert scale ranging from 1 (strongly disagree) to 4 (strongly agree). In our sample, the Cronbach's $\alpha$ value was 0.83 .

Machiavellianism was measured using a German version (Henning and Six, 1977) of the MACH-IV Inventory (Christie and Geis, 1970). All of the 18 Machiavellianism items were answered on a six-point Likert scale ranging from 1 (not true at all) to 6 (absolutely true). The following item serves as a sample: "Never tell anyone the real reason you did something unless it is useful to do so". With respect to the scale's reliability, we obtained a Cronbach's $\alpha$ of 0.84 .

Finally, psychopathy was operationalised by the Levenson's self-report psychopathy scale (LSRP; Levenson et al., 1995). This questionnaire contains 26 items representing the psychopathic emotional affect (16 items) and the psychopathic lifestyle (10 items). All of the items were completed on a four-point Likert scale ranging from 1 (strongly disagree) to 4 (strongly agree). The following item serves as a sample: "Success is based on survival of the fittest; I am not concerned about the losers". We used the composite psychopathy score (summed score) and received a Cronbach's $\alpha$ of 0.79 .

Objective career success. Salary. In accordance with Judge et al. (1999), the participants were asked to rate their yearly pre-tax income. Six categories ranging from less than 24,000 euros to more than 84,000 euros were used and subsequently coded from 1 to 6 with higher scores reflecting higher salaries.

Leadership position. The participants were asked if they were currently holding a leadership position. Their answer was binary coded with 0 representing that the participants had no leadership responsibilities and 1 representing that they were responsible for staff (see also: Spurk et al., 2016).

Subjective career success. Job satisfaction. To assess the participants' job satisfaction, we employed the corresponding dimension of Fahrenberg et al.'s (2000) Life Satisfaction Questionnaire. This dimension consists of seven items, which are completed on a seven-point Likert scale ranging from 1 (totally dissatisfied) to 7 (totally satisfied). Some sample items of this scale are "Concerning my success at work I am [...]" or "When I think of my employment security in the future, I am [...]". With respect to the scale's reliability, we obtained a Cronbach's $\alpha$ value of 0.83 .

Satisfaction with income. Satisfaction with personal income was operationalised using the corresponding dimension of Fahrenberg et al.'s (2000) Life Satisfaction Questionnaire. The answers to the seven items of this dimension were provided on a seven-point Likert scale ranging from 1 (totally dissatisfied) to 7 (totally satisfied). The following item serves as a sample: "With my income/salary I am [...]". In our sample, Cronbach's $\alpha$ value was 0.90 .

Control variables. Gender, age and weekly working hours were considered control variables. Gender and weekly working hours were dummy-coded with 0 representing the female gender, 1 representing the male gender, 0 representing part-time employment (30 working hours), and 1 representing full-time employment. Age was measured in years.

\section{Results}

Intercorrelations among all variables, obtained Cronbach's $\alpha$ values (see main diagonal), and means and standard deviations are depicted in Table I. Cronbach's $\alpha$ values ranged from 0.74 to 0.90 and show acceptable to good reliability for all of the employed measurements. Correlations among the Dark Triad and between the dark traits and the Big Five closely resemble those reported by Furnham et al. (2014). All of the dark traits are positively related 
to each other with Machiavellianism and psychopathy showing the strongest association $(r=0.63, p<0.01)$. Regarding the relationship between the dark and the bright traits, the highest correlation can be reported between psychopathy and agreeableness $(r=-0.65$, $p<0.01$ ).

Table II summarises the results of the regressions where the dark traits were included in the last step to clarify if they provide incremental or redundant information to the Big Five when forecasting career success. With respect to the Dark Triad's incremental value, the results support $H 1$ and $H 2$ : the Dark Triad adds validity when predicting salary $\left(H 1: \Delta R^{2}=0.02, p<0.05\right)$ and leadership position $\left(H 2: \Delta R^{2}=0.04, p<0.05\right)$. Regarding the direction of the effects and the relative importance of the three dark traits, the $\beta$-values in Table II further show that only narcissism predicts salary and leadership position in a positive way $\left(\beta_{\text {salary }}=0.16, p<0.05 ; \operatorname{Exp}(B)_{\text {leadership position }}=7.36, p<0.01\right)$. Psychopathy predicts salary in a negative way $\left(\beta_{\text {salary }}=-0.19, p<0.05\right)$; however, Machiavellianism does not significantly predict objective career success. With respect to the logistic regression on leadership position, the predicted probabilities were calculated for a deeper understanding of the results. The predicted probabilities indicate that 70.8 per cent of all of the study participants are correctly classified regarding their leadership position (yes/no) when solely using the Big Five as predictor variables. When the Dark Triad traits are added in a second step, the number of correctly classified participants significantly increases to 74.3 per cent.

In contrast to $H 1$ and $H 2, H 3$ and $H 4$, which refer to the Dark Triad's incremental value when predicting subjective success evaluations, are not supported. In fact, the results show that the Dark Triad's inclusion does not result in an increase of the explained variance when it comes to the subjective criteria of job satisfaction $\left(\Delta R^{2}=0.00, \mathrm{~ns}\right)$ and satisfaction with income $\left(\Delta R^{2}=0.00, \mathrm{~ns}\right)$.

Collectively, personality traits (i.e. the Dark Triad and the Big Five) explain 20 per cent of the variance of job satisfaction, 13 per cent of the variance of satisfaction with income, 6 per cent of the variance of salary and 13 per cent of the variance of leadership position. Importantly, all these analyses were controlled for age, gender and weekly working hours.

\section{Discussion}

This study is the first to simultaneously investigate the Dark Triad and the Big Five regarding career success. Our results show that the Dark Triad adds incremental information beyond the Big Five when predicting the career success criteria of salary and leadership position. They further demonstrate that the incremental value of the Dark Triad depends on the chosen success criterion. In fact, the Dark Triad does not add to the prediction of job satisfaction and satisfaction with income.

The current findings contribute to various respects of recent research. First, they extend the study of Spurk et al. (2016) by showing that it seems justified to use the Dark Triad as an additional predictor for career success. Second, they strengthen the assumptions of Veselka and Vernon (2014) and Harms and Spain (2015), who state that the dark side of personality is not adequately represented by the Big Five. Third, the results suggest that the unique information provided by the Dark Triad depends on the chosen criterion. Finally, the current findings propose that the socioanalytic theory offers a potential explanation on how the Dark Triad relates to career success and why it adds incremental validity over the Big Five.

\section{The Dark Triad complements the Big Five}

The Dark Triad complements the Big Five when predicting career success but this only holds true for specific criteria. With respect to the current findings, the Dark Triad adds incremental validity over the Big Five when predicting salary and leadership position but 
JMP

33,6

448

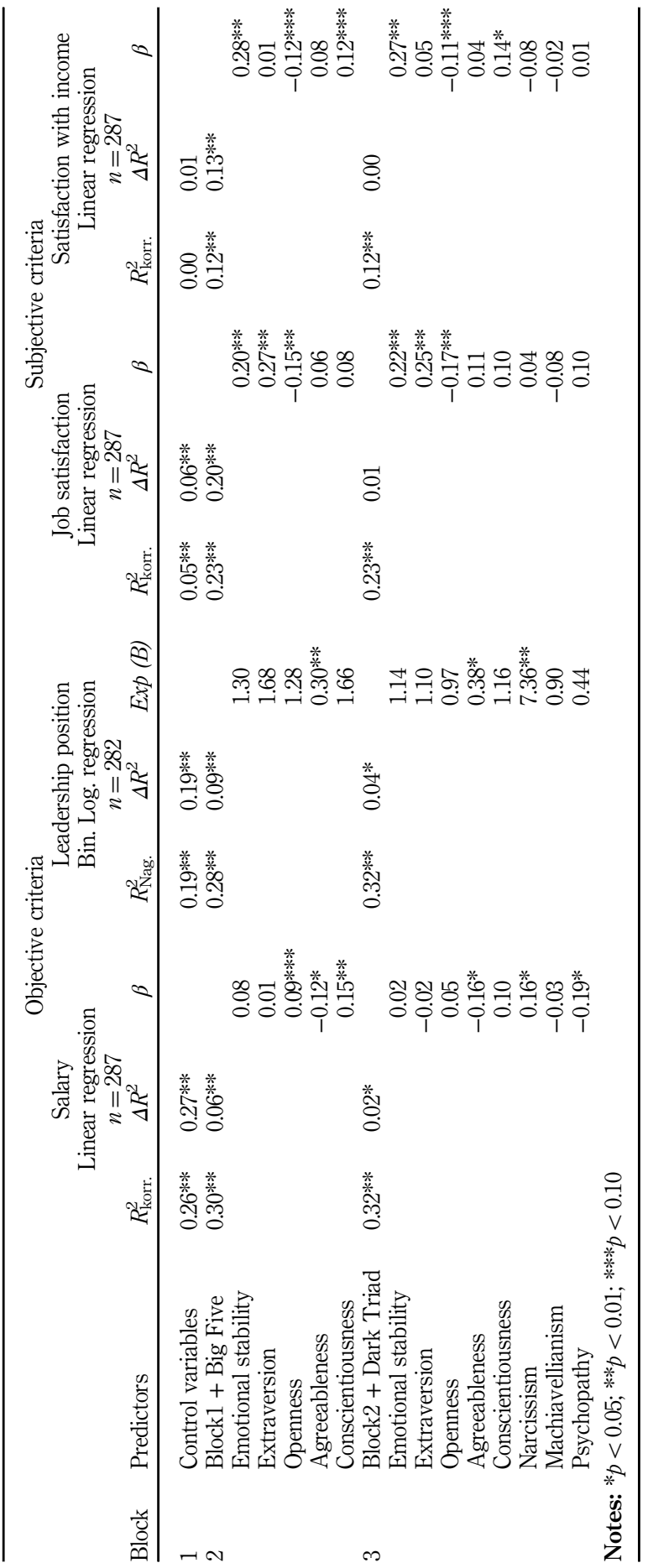

Table II.

Regression analyses on career success when entering the Dark Triad in the last step 
not when forecasting job satisfaction or satisfaction with income. We argue that this finding is tied to the circumstance that different attitudinal and behavioural antecedents underlie these criteria.

This reasoning is inspired by Oh and Berry (2009), who combined the trait approach and the socioanalytic theory (Hogan and Holland, 2003) when predicting work performance. Based on their findings, it is suggested that certain traits trigger certain behaviour strategies, which are predominantly relevant for certain aspects of work performance. In the current study, we extend this finding to the context of career success and therewith also address Jonason et al.'s (2014) advice to more strongly focus on the question of why personality traits lead to specific behaviour strategies that result in specific outcomes. We argue in detail that traits in general are distal predictors of career-related outcomes, which influence these outcomes through more proximal predictors such as behaviour strategies (see also Judge et al., 2009).

According to socioanalytic theory, behaviour strategies can be divided along two evolutionary-anchored motive patterns, which are termed "getting-ahead" and "getting-along". We suggest that the Big Five's validity in predicting criteria that are strongly influenced by getting-ahead behaviour is limited because the Big Five are seen as getting-along-centred when compared to the Dark Triad. The results of this study are in agreement with this reasoning and clearly support the use of the Dark Triad in addition to the Big Five when predicting the getting-ahead-driven criteria of salary and leadership position. The findings that the Dark Triad does not offer incremental validity over the Big Five when forecasting job satisfaction and satisfaction with income likewise suggests that the importance of a person's darker personality is limited when predicting criteria that are better achieved by getting-along behaviour. Even though according to Spurk et al. (2016) the Dark Triad predicts subjective career success, it cannot offer additional information beyond the Big Five when answering the question as to how satisfied individuals will be with their jobs and incomes.

Despite the benefits that come along when using the Dark Triad in an occupational context, it should be highlighted that the predominance of the Big Five model resulted in undeniable advantages. The wide acceptance of the Big Five taxonomy has led to its frequent use, which enhances the comparability of the research results and leads to a better communication regarding non-cognitive personality traits. Therefore, moving away from this accordance by focusing on other personality measures comes along with certain costs. Consequently, we recommend a thoughtful evaluation before using the Dark Triad instead of or in combination with the Big Five. More precisely, we suggest employing the Dark Triad when conducting research in a competitive context where getting-ahead behaviour is of particular importance.

With regard to a combined method of measuring darker and brighter personality aspects, the HEXACO model might be a fruitful alternative as it covers the common core of the Dark Triad (through the honesty-humility dimension) and the brighter traits associated with the Big Five (Lee and Ashton, 2014). For example, Book et al. (2015) proved in a direct comparison of various models that allegedly account for the Dark Triad traits' overlap, that the HEXACO model outperforms the Big Five in this regard. However, if the Dark Triad can also enhance the predictions of the HEXACO model when forecasting career success is still unexplored and needs to be investigated in further studies. Next to the HEXACO model, another approach for conjointly studying brighter and darker traits might occur in the formation of so-called aberrant personality compounds. As suggested by Wille et al. (2013), the Five-Factor model may be used for such compounds, which are individual-based indicators of aberrant personality tendencies.

\section{The Dark Triad positively and negatively impacts career success}

Our results suggest that the three dark traits affect career success in a very distinct manner. While narcissism predicts success in a positive way, Machiavellianism is unrelated and 
JMP

33,6

psychopathy is negatively related to career success. The varying importance of the three dark traits might be explained by the circumstance that each of these traits is expressed by different behaviours that are perceived by others either in a more positive or negative way. In other words, the behaviour triggered by the three traits varies largely with respect to how it is perceived by others.

According to our findings and previously published studies (Rauthmann and Kolar, 2012), narcissism is perceived to be the "brightest" trait among the Dark Triad. Results of this study resemble those of Spurk et al. (2016) and show that individuals with a high level of narcissism receive higher income and more often take on leadership roles. One reason for the positive narcissism-career success link might be that narcissism positively relates to traits that are important for the occupational world. For example, narcissists show more perseverance and higher motivation in completing non-solvable tasks (Wallace et al., 2009). Additionally, narcissists display higher self-efficacy and report a higher internal locus of control and higher entrepreneurial tendencies (Mathieu and St-Jean, 2013). These traits are undoubtedly important in the occupational world and may either lead to good impression management or simply to more effort, which enhances the chance to climb the career ladder and increases personal income. Based on these arguments, it is assumed that narcissistic tendencies are to a certain extent positively perceived by others. Furthermore, narcissists may less frequently exceed normative borders when interacting with others compared to Machiavellians or psychopaths.

The negative relationship between psychopathy and career success may be rooted in other differences. For example, psychopaths are highly reactive to stress (Noser et al., 2014) and tend to make poor financial decisions by mismanaging other people's money even when expecting punishment (Jones, 2014). If such behaviour is applied in an organisational context, it most probably hinders career advancement and further jeopardises organisational success. Moreover, psychopaths lack self-related and other-related qualities that are tied to success at work. For instance, they show poor self-leadership, self-goal setting and self-observation (Furtner et al., 2011). With respect to others, they lack concern for other people or social norms and primarily use hard tactics to achieve their goals that often go beyond acceptable behaviour. Acting in such a way could also influence the organisational climate in a negative way and thus could result in negative consequences that occur with a harmful organisational climate. As a consequence, psychopathy may be perceived as more negative than narcissism.

With respect to Machiavellianism, no link with career success was found in this study. These findings are not in agreement with those reported by Spurk et al. (2016). One possible explanation might lie in the difference between the sample employed in this study versus the sample recruited by Spurk et al. While Spurk et al. investigated persons in their early career stages, the participants in this study reported an average career duration of 17 years and thus are more experienced and at a senior level. As Machiavellians favour short-term over long-term strategies and therefore only reveal their negative sides after deeper examination, their negative sides might not be revealed during earlier career stages (e.g. Jonason et al., 2009; Wilson et al., 1998).

An additional explanation for the non-significant Machiavellianism-success effect is provided by O'Boyle et al. (2012), who meta-analytically demonstrated that correlations between Machiavellianism and job performance show large variability. This instability of the Machiavellianism-performance effect might relate to the difference between the intention and the ability to manipulate others. If the intention and the ability to manipulate is high, then manipulation attempts will most likely be successful. If the intention to manipulate others is high while the ability to do so is rather low, then manipulation attempts will most likely be revealed, which will lead to more costs than benefits. During social interactions, it is expected that people ignore, avoid, or even punish others once they realise that they have been manipulated on purpose. 
Similarly, Touhey (1973) showed that Machiavellianism solely results in upward social mobility when paired with higher levels of intelligence. When high tendencies of Machiavellianism were combined with lower intelligence the opposite effect was reported. In addition, situational contexts strongly influence the way Machiavellianism affects workrelated outcomes. For example, personal success in marketing positively correlates with Machiavellianism only in settings offering a high chance for improvisation (Sparks, 1994). As our study considers neither intelligence nor the degree of improvisation as moderating variables, it is possible that potential effects cannot be detected as they are simply cancelled out. However, considering that Wilson et al. (1996) listed positive, negative and insignificant links between Machiavellianism and success criteria and also considering that this particular link is influenced by diverse moderators, it is not necessarily surprising that our findings differ from Spurk et al. (2016).

\section{Limitations and future research}

As with any study there are limitations to consider. First, this study solely uses self-rated success criteria. Although self-ratings are not seen as highly problematic in measuring objective career success (Seibert et al., 1999; Podsakoff and Organ, 1986) and might be among the most valid ways to measure attitudinal constructs, such as job satisfaction or satisfaction with income, they still increase the risk of possible same-source biases. Future studies should thus include ratings derived from multiple perspectives (e.g. supervisor-ratings) to better calculate this risk. Nevertheless, it needs to be emphasised that the study of career success and dark traits is in its early stages. Therefore, studies using self-reports and cross-sectional designs may provide a valuable basis for future research.

Second, future research should employ direct measures of getting-ahead and gettingalong behaviours to provide a more comprehensive test of the psychological processes proposed in our model. Replication with other measures of the Dark Triad (e.g. the Dirty Dozen) (Jonason and Webster, 2010) might also allow for a more precise test of our hypotheses. Third, as this is the first investigation on career success that simultaneously focuses on the impact of the Dark Triad and the Big Five, there are plenty of questions that remain unanswered. For instance, are the observed relationships sensitive to changes in the bandwidth or fidelity and does the Dark Triad add relevant information concerning career success to individual Big Five facets? Are positive effects on career success generalisable to other success domains? For example, future research should examine whether it is only the individual that profits from narcissistic tendencies or if this profit can be transferred to an organisational level. Moreover, it would be interesting to know whether the Dark Triad adds incremental validity over the HEXACO model when predicting career success. As the HEXACO model includes the honesty-humility factor, which (on its negative pole) reflects aspects of the Dark Triad, it is assumed that the Dark Triad adds less validity over the HEXACO factors than over the Big Five factors. However, as (very low) honesty-humility primarily echoes the common core of the Dark Triad traits but not their full bandwidth, it is further suggested that the Dark Triad adds at least a certain amount of incremental validity over the HEXACO factors. Additionally, it could be profitable to consider situational moderators such as job tenure, industry, job requirements or job autonomy when studying the relationship between dark traits and career success. Taking these moderators into account could even lead to stronger relationships between the Dark Triad and career success. Furthermore, it could be examined whether specific interactions between dark and bright traits and cognitive abilities are particularly promising with respect to career success. Finally, longitudinal analyses are needed to clarify whether a certain characteristic of dark traits is the cause or consequence of career success. 
JMP

33,6

\section{Conclusion}

In summary, this study is the first that simultaneously investigates all three traits of the Dark Triad and the Big Five in combination with objective and subjective career success. It extends previous findings by answering the question of whether the Dark Triad offers incremental or redundant information to the Big Five when predicting success. Considering the Dark Triad in employee selection and development seems particularly promising when the prediction of criteria in the context of getting-ahead is the central focus.

\section{References}

Abele, A.E., Spurk, D. and Volmer, J. (2011), "The construct of career success. measurement issues and an empirical example", Zeitschrift für ArbeitsmarktForschung, Vol. 43 No. 3, pp. 195-206.

Adler, A. (1939), Social Interest, G.P. Putnam's Sons, New York, NY.

Akhtar, R., Ahmetoglu, G. and Chamorro-Premuzic, T. (2013), "Greed is good? Assessing the relationship between entrepreneurship and subclinical psychopathy", Personality and Individual Differences, Vol. 54 No. 3, pp. 420-425.

Andreassen, C.S., Ursin, H., Eriksen, H.R. and Pallesen, S. (2012), "The relationship of narcissism with workaholism, work engagement, and professional position”, Social Behavior and Personal, Vol. 40 No. 6, pp. 881-890.

Anninos, L.N. (2018), "Narcissistic business leaders as heralds of the self-proclaimed excellence", International Journal of Quality and Service Sciences, Vol. 10 No. 1, pp. 49-60.

Arrindell, W.A., van Nieuwenhuizen, C. and Luteijn, F. (2001), "Chronic psychiatric status and satisfaction with life", Personality and Individual Differences, Vol. 31 No. 2, pp. 145-155.

Babiak, P. and Hare, R.D. (2006), Snakes in Suits: When Psychopaths Go To Work, 1st ed., Regan Books, New York, NY.

Bakan, D. (1966), The Duality of Human Existence: Isolation and Communion in Western Man, Vol. 395, Beacon Paperback, Beacon and Boston, MA.

Barrick, M.R. and Mount, M.K. (1991), "The big five personality dimensions and job performance. A meta-analysis”, Personnel Psychology, Vol. 44 No. 1, pp. 1-26.

Barrick, M.R., Mount, M.K. and Judge, T.A. (2001), "Personality and performance at the beginning of the new millennium. what do we know and where do we go next?", International Journal of Selection and Assessment, Vol. 9 Nos 1/2, pp. 9-30.

Barrick, M.R., Stewart, G.L. and Piotrowski, M. (2002), "Personality and job performance. test of the mediating effects of motivation among sales representatives", Journal of Applied Psychology, Vol. 87 No. 1, pp. 43-51.

Boddy, C.R., Ladyshewsky, R.K. and Galvin, P. (2010), "The influence of corporate psychopaths on corporate social responsibility and organizational commitment to employees", Journal of Business Ethics, Vol. 97 No. 1, pp. 1-19.

Book, A., Visser, B.A. and Volk, A.A. (2015), "Unpacking 'evil': claiming the core of the Dark Triad", Personality and Individual Differences, Vol. 73, pp. 29-38.

Boudreau, J.W., Boswell, W.R. and Judge, T.A. (2001), "Effects of personality on executive career success in the United States and Europe", Journal of Vocational Behavior, Vol. 58 No. 1, pp. 53-81.

Brunell, A.B., Gentry, W.A., Campbell, W.K., Hoffman, B.J., Kuhnert, K.W. and Demarree, K.G. (2008), "Leader emergence. the case of the narcissistic leader", Personality \& Social Psychology Bulletin, Vol. 34 No. 12, pp. 1663-1676.

Cable, D.M. and Judge, T.A. (2003), "Managers' upward influence tactic strategies. the role of manager personality and supervisor leadership style”, Journal of Organizational Behavior, Vol. 24 No. 2 , pp. 197-214.

Campbell, W.K. and Foster, C.A. (2002), "Narcissism and commitment in romantic relationships: an investment model analysis", Personality \& Social Psychology Bulletin, Vol. 28 No. 4, pp. 484-495. 
Christie, R. and Geis, F.L. (1970), Studies in Machiavellianism, Social Psychology, Academic Press, New York.

Costa, P.T. and McCrae, R.R. (1992), Revised NEO Personality Inventory (NEO PI-R) and NEO Five-Factor Inventory (NEO-FFI), Psychological Assessment Resources, Odessa, Fl.

Dahling, J.J., Whitaker, B.G. and Levy, P.E. (2008), "The development and validation of a new Machiavellianism scale", Journal of Management, Vol. 35 No. 2, pp. 219-257.

Darwin, C. (2013), On The Origin of The Species, Lexington, KY.

Dawkins, R. (1976), The Selfish Gene, Oxford University Press, Oxford.

Fahrenberg, J., Myrtek, M., Schumacher, J. and Brähler, E. (2000), FLZ: Fragebogen zur Lebenszufriedenheit; Handanweisung, Hogrefe Verlag für Psychologie, Göttingen.

Foote, D.A. and Li-Ping Tang, T. (2008), "Job satisfaction and organizational citizenship behavior (OCB)", Management Decision, Vol. 46 No. 6, pp. 933-947.

Furnham, A., Richards, S.C. and Paulhus, D.L. (2013), "The Dark Triad of personality: a 10 year review", Social and Personality Psychology Compass, Vol. 7 No. 3, pp. 199-216.

Furnham, A., Richards, S., Rangel, L. and Jones, D.N. (2014), "Measuring malevolence. quantitative issues surrounding the Dark Triad of personality", Personality and Individual Differences, Vol. 67, pp. 114-121.

Furtner, M.R., Rauthmann, J.F. and Sachse, P. (2011), “The self-loving self-leader: an examination of the relationship between self-leadership and the Dark Triad", Social Behavior and Personality: An International Journal, Vol. 39 No. 3, pp. 369-379.

Gurtman, M.B. (1992), "Trust, distrust, and interpersonal problems: a circumplex analysis", Journal of Personality and Social Psychology, Vol. 62 No. 6, pp. 989-1002.

Harms, P.D. and Spain, S.M. (2015), "Beyond the bright side. Dark personality at work", Applied Psychology, Vol. 64 No. 1, pp. 15-24.

Henning, H.J. and Six, B. (1977), "Konstruktion einer Machiavellismusskala", Zeitschrift für Sozialpsychologie, Vol. 8, pp. 185-198.

Heslin, P.A. (2005), "Conceptualizing and evaluating career success", Journal of Organizational Behavior, Vol. 26 No. 2, pp. 113-136.

Hogan, J. and Holland, B. (2003), "Using theory to evaluate personality and job-performance relations. a socioanalytic perspective", Journal of Applied Psychology, Vol. 88 No. 1, pp. 100-112.

Hogan, R. (1983), "A socioanalytic theory of personality", in Page, M.M. and Pervin, L.A. (Eds), Personality - Current Theory and Research, Nebraska Symposium on Motivation, University of Nebraska Press, Lincoln, pp. 55-89.

Hughes, E.C. (1937), "Institutional office and the person”, American Journal of Sociology, Vol. 43 No. 3, p. 404.

Hülsheger, U.R. and Maier, G.W. (2008), "Persönlichkeitseigenschaften, Intelligenz und Erfolg im Beruf. Eine Bestandsaufnahme internationaler und nationaler Forschung", Psychologische Rundschau, Vol. 59 No. 2, pp. 108-122.

Jonason, P.K. and Tost, J. (2010), "I just cannot control myself: the Dark Triad and self-control", Personality and Individual Differences, Vol. 49 No. 6, pp. 611-615.

Jonason, P.K. and Webster, G.D. (2010), "The dirty dozen: a concise measure of the Dark Triad", Psychological Assessment, Vol. 22 No. 2, pp. 420-432.

Jonason, P.K., Slomski, S. and Partyka, J. (2012), "The Dark Triad at work: how toxic employees get their way”, Personality and Individual Differences, Vol. 52 No. 3, pp. 449-453.

Jonason, P.K., Wee, S. and Li, N.P. (2014), “Thinking bigger and better about 'bad apples'. Evolutionary industrial-organizational psychology and the Dark Triad”, Industrial and Organizational Psychology, Vol. 7 No. 1, pp. 117-121. 
JMP

33,6

Jonason, P.K., Wee, S. and Li, N.P. (2015), "Competition, autonomy, and prestige: mechanisms through which the Dark Triad predict job satisfaction”, Personality and Individual Differences, Vol. 72, pp. 112-116.

Jonason, P.K., Li, N.P., Webster, G.D. and Schmitt, D.P. (2009), "The Dark Triad: facilitating a short-term mating strategy in men”, European Journal of Personality, Vol. 23 No. 1, pp. 5-18.

Jones, D.N. (2014), "Risk in the face of retribution. psychopathic individuals persist in financial misbehavior among the Dark Triad", Personality and Individual Differences, Vol. 67, pp. 109-113.

Judge, T.A., Bono, J.E., Ilies, R. and Gerhardt, M.W. (2002), "Personality and leadership: a qualitative and quantitative review", Journal of Applied Psychology, Vol. 87 No. 4, pp. 765-780.

Judge, T.A., Cable, D.M., Boudreau, J.W. and Bretz, R.D. (1995), "An empirical investigation of the predictors of executive career success”, Personnel Psychology, Vol. 48 No. 3, pp. 485-519.

Judge, T.A., Heller, D. and Mount, M.K. (2002), "Five-Factor model of personality and job satisfaction: a meta-analysis", Journal of Applied Psychology, Vol. 87 No. 3, pp. 530-541.

Judge, T.A., Piccolo, R.F. and Kosalka, T. (2009), "The bright and dark sides of leader traits. a review and theoretical extension of the leader trait paradigm", The Leadership Quarterly, Vol. 20 No. 6, pp. 855-875.

Judge, T.A., Higgins, C.A., Thoresen, C.J. and Barrick, M.R. (1999), "The big five personality traits, general mental ability, and career success across the life span”, Personnel Psychology, Vol. 52 No. 3, pp. 621-652.

Kessler, S.R., Bandelli, A.C., Spector, P.E., Borman, W.C., Nelson, C.E. and Penney, L.M. (2010), "Re-examining Machiavelli. a three-dimensional model of Machiavellianism in the workplace", Journal of Applied Social Psychology, Vol. 40 No. 8, pp. 1868-1896.

Lee, K. and Ashton, M.C. (2004), "Psychometric properties of the HEXACO personality inventory", Multivariate Behavioral Research, Vol. 39 No. 2, pp. 329-358.

Lee, K. and Ashton, M.C. (2014), "The Dark Triad, the big five, and the HEXACO model”, Personality and Individual Differences, Vol. 67, pp. 2-5.

Levenson, M.R., Kiehl, K.A. and Fitzpatrick, C.M. (1995), "Assessing psychopathic attributes in a noninstitutionalized population", Journal of Personality and Social Psychology, Vol. 68 No. 1, pp. 151-158.

Lilienfeld, S.O., Latzman, R.D., Watts, A.L., Smith, S.F. and Dutton, K. (2014), "Correlates of psychopathic personality traits in everyday life: results from a large community survey", Frontiers in Psychology, Vol. 5, pp. 740-751.

Liu, C.C. (2008), "The relationship between machiavellianism and knowledge sharing willingness", Journal of Business and Psychology, Vol. 22 No. 3, pp. 233-240.

Locke, K.D. and Christensen, L. (2007), "Re-construing the relational-interdependent self-construal and its relationship with self-consistency", Journal of Research in Personality, Vol. 41 No. 2, pp. 389-402.

Lyubomirsky, S., Sheldon, K.M. and Schkade, D. (2005), "Pursuing happiness: the architecture of sustainable change", Review of General Psychology, Vol. 9 No. 2, pp. 111-131.

Margulis, L. (Ed.) (1991), Symbiosis as a Source of Evolutionary Innovation: Speciation and Morphogenesis, MIT Pr, Cambridge, MA.

Mathieu, C. (2013), "Personality and job satisfaction: the role of narcissism", Personality and Individual Differences, Vol. 55 No. 6, pp. 650-654.

Mathieu, C. and St-Jean, É. (2013), "Entrepreneurial personality", The Role of Narcissism”, Personality and Individual Differences, Vol. 55 No. 5, pp. 527-531.

Morf, C.C. and Rhodewalt, F. (2016), "Narcissism and self-evaluation maintenance: explorations in object relations”, Personality \& Social Psychology Bulletin, Vol. 19 No. 6, pp. 668-676.

Ng, T.W.H., Eby, L.T., Sorensen, K.L. and Feldman, D.C. (2005), "Predictors of objective and subjective career success: a meta-analysis”, Personnel Psychology, Vol. 58 No. 2, pp. 367-408. 
Noser, A.E., Zeigler-Hill, V. and Besser, A. (2014), "Stress and affective experiences: the importance of dark personality features", Journal of Research in Personality, Vol. 53, pp. 158-164.

O'Boyle, E.H., Forsyth, D.R., Banks, G.C. and McDaniel, M.A. (2012), "A meta-analysis of the Dark Triad and work behavior: a social exchange perspective", The Journal of Applied Psychology, Vol. 97 No. 3, pp. 557-579.

Oh, I.-S. and Berry, C.M. (2009), "The Five-Factor model of personality and managerial performance: validity gains through the use of 360 degree performance ratings", The Journal of Applied Psychology, Vol. 94 No. 6, pp. 1498-1513.

Oppriessnig, S. and Neubauer, A. (2012), "Neo-PI-R-90”, Unpublished manuscript, Karl-FranzensUniversität Graz.

Osumi, T. and Ohira, H. (2010), "The positive side of psychopathy: emotional detachment in psychopathy and rational decision-making in the ultimatum game", Personality and Individual Differences, Vol. 49 No. 5, pp. 451-456.

Paulhus, D.L. and Williams, K.M. (2002), “The Dark Triad of personality: narcissism, machiavellianism, and psychopathy", Journal of Research in Personality, Vol. 36 No. 6, pp. 556-563.

Podsakoff, P.M. and Organ, D.W. (1986), "Self-reports in organizational research: problems and prospects", Journal of Management, Vol. 12 No. 4, pp. 531-544.

Raskin, R.N. and Hall, C.S. (1979), “A narcissistic personality inventory”, Psychological Reports, Vol. 45 No. 2, p. 590.

Rauthmann, J.F. and Kolar, G.P. (2012), "How 'dark' are the Dark Triad traits? Examining the perceived darkness of narcissism, machiavellianism, and psychopathy", Personality and Individual Differences, Vol. 53 No. 7, pp. 884-889.

Rowold, J. and Heinitz, K. (2007), "Transformational and charismatic leadership: assessing the convergent, divergent and criterion validity of the MLQ and the CKS", The Leadership Quarterly, Vol. 18 No. 2, pp. 121-133.

Seibert, S.E. and Kraimer, M.L. (2001), "The Five-Factor model of personality and career success", Journal of Vocational Behavior, Vol. 58 No. 1, pp. 1-21.

Seibert, S.E., Crant, J.M. and Kraimer, M.L. (1999), "Proactive personality and career success", Journal of Applied Psychology, Vol. 84 No. 3, pp. 416-427.

Smith, M.B., Hill, A.D., Wallace, J.C., Recendes, T. and Judge, T.A. (2017), "Upsides to dark and downsides to bright personality. A multidomain review and future research agenda", Journal of Management, Vol. 44 No. 1, pp. 191-217.

Sparks, J.R. (1994), "Machiavellianism and personal success in marketing. the moderating role of latitude for improvisation”, Journal of the Academy of Marketing Science, Vol. 22 No. 4, pp. 393-400.

Spurk, D., Keller, A.C. and Hirschi, A. (2016), "Do bad guys get ahead or fall behind? Relationships of the Dark Triad of personality with objective and subjective career success", Social Psychological and Personality Science, Vol. 7 No. 2, pp. 113-121.

Tang, T.L.-P. and Chen, Y.-J. (2008), "Intelligence vs. wisdom: the love of money, Machiavellianism, and unethical behavior across college major and gender", Journal of Business Ethics, Vol. 82 No. 1, pp. 1-26.

Touhey, J.C. (1973), "Intelligence, machiavellianism and social mobility", British Journal of Social and Clinical Psychology, Vol. 12 No. 1, pp. 34-37.

van Vugt, M. and Tybur, J.M. (2016), "The evolutionary foundations of status hierarchy”, in Buss, D.M. (Ed.), The Handbook of Evolutionary Psychology, John Wiley \& Sons, Inc, Hoboken, NJ, USA, pp. 788-809.

Veselka, L. and Vernon, P.A. (2014), "Introduction to the special issue on the Dark Triad and related traits", Personality and Individual Differences, Vol. 67, p. 1.

Voight, K. (2012), "Bad bosses. the psycho-path to success", available at: http://edition.cnn.com/2012/0 1/19/business/psychopath-boss/ (accessed 22 August 2018). 
Wallace, H.M., Ready, C.B. and Weitenhagen, E. (2009), "Narcissism and task persistence", Self and Identity, Vol. 8 No. 1, pp. 78-93.

Wiggins, J.S. (1991), Manual for The Interpersonal Adjective Scales, Psychological Assessment Resources, Odessa, Fl.

Wille, B., De Fruyt, F. and De Clercq, B. (2013), "Expanding and reconceptualizing aberrant personality at work: validity of Five-Factor model aberrant personality tendencies to predict career outcomes", Personnel Psychology, Vol. 66 No. 1, pp. 173-223.

Wilson, D., Near, D.C. and Miller, R.R. (1998), "Individual differences in Machiavellianism as a mix of cooperative and exploitative strategies", Evolution and Human Behavior, Vol. 19 No. 3, pp. 203-212.

Wilson, D.S., Near, D. and Miller, R.R. (1996), "Machiavellianism. a synthesis of the evolutionary and psychological literatures", Psychological Bulletin, Vol. 119 No. 2, pp. 285-299.

Wisse, B. and Sleebos, E. (2016), "When the dark ones gain power: perceived position power strengthens the effect of supervisor Machiavellianism on abusive supervision in work teams", Personality and Individual Differences, Vol. 99, pp. 122-126.

Xanthopoulou, D., Bakker, A.B., Demerouti, E. and Schaufeli, W.B. (2009), "Work engagement and financial returns: a diary study on the role of job and personal resources", Journal of Occupational and Organizational Psychology, Vol. 82 No. 1, pp. 183-200.

Zimmermann, J. (1994), "Metrische Erfassung der Persönlichkeitsdimension "Narzißmus" bei Normalpersonen, Patienten mit narzißtischen Persönlichkeitsstörungen und anderen Persönlichkeitsstörungen”, Unpublished manuscript, RWTH Aachen.

\section{Corresponding author}

Dominik Paleczek can be contacted at: dominik.paleczek@uni-graz.at

For instructions on how to order reprints of this article, please visit our website: 